\title{
EUROPEAN
}

DOI: 10.1515/ep-2015-0002

Ryszard Jaworski"

\section{Observations from the Analysis of Searching Peak of Tension Test (SPOT) Charts}

Key Words: Peak of Tension Test (POT), Searching Peak of Tension (SPOT)

\section{Introduction}

A technique applied in polygraph examinations is a variant of the CIT test, known as the Peak of Tension Type B (7), Searching POT Test (2,3), Probing Peak of Tension Test (18), and Keeler POT Type B (2). J.A. Matte describes the application of the technique in the following way:

'Another type of Peak of Tension Test available to the forensic psycho-physiologist is known as the Probing Peak of Tension Test. This test is used to identify key information not known to the investigator or the forensic psychophysiology. It may be used to locate accomplices, determine extent of involvement, locate weapons, loot,

\footnotetext{
*rjaworsk@prawo.uni.wroc.pl
} 
evidence, determine amounts of money stolen, and methods of entry. (...) Probing POT tests should be prepared prior to the scheduled examination with a view towards determining those facts deemed most important to the investigator in solving their case' (18). A similar comment is found in N. Ansley: 'The Searching Peak of Tension tests were to be used to locate evidence or identify accomplices' (2).

D. Lykken writes the following on the subject of the test's legal significance: 'The Searching Peak of Tension test is its own justification when it leads to the discovery of useful physical evidence or elicits a valid confession. The mere occurrence of consistent responding to some item in the series, by itself, is hopelessly ambiguous and provides no legitimate basis for any conclusions about the veracity of the subject' (17).

The National Research Council's (NRC) report on the test includes a similar claim: 'It is also possible to use the peak-of-tension test in a searching mode when the examiner does not know which answer is connected to the event but wants to use the test for help in an investigation. It is assumed that the pattern of a guilty person's autonomic responses will reveal the correct answer' (20). All authors agree about the significance of the tests: they are auxiliary, supplementary tests, which should be applied following CQT tests if the subject reacts to relevant questions included in these tests. Also the APA (American Polygraph Association) classification from 2011 considers SPOT test as auxiliary (screening) tests, lacking evidential value (6).

Despite such an assessment of their evidential value, no one calls for abandoning the use of the tests. Literature argues that the result of a polygraph examination should not be assessed solely as incriminating evidence used to convict a criminal. It may facilitate an investigation, which - as confirmed by the NRC assessment quoted above - is particularly relevant for SPOT tests. In Polish literature, this is emphasised by J. Widacki, who argues that SPOT tests may be helpful at the preliminary stages of an investigation, as they enable discovering material evidence or accomplices. At further stages the evidence becomes the grounds for establishing facts in its own right (28).

Use of SPOT test is necessary in case of the evidence which Matte mentions in reference to organised crime. The system of justice will benefit even if evidence is acquired only in some cases within this category. Other important reasons to use SPOT tests include (e.g. in Japan) cases of missing people. Makoto Nakayama refers to them when he writes that 'when a person disappears suddenly and motives of suicide or escape have been ruled out, police investigators must consider homicide as an option. Detectives investigate the existence of motives and suspects. Though it is difficult to compose CIT sequences in the circumstances, SPOT-containing questions concerning the date, place, method, manner of murder, and disposal of the corpse may be 
utilised. However, we cannot be certain that the sequences contain correct items of critical information, because they are unknown, except to the culprit' (19).

In cases of homicide and disappearance of a person it is advisable to complement the CQT technique with other tests for an additional reason, as the results may be less accurate than in cases of theft or robbery. We should take into account the difficulty in preparing control questions emotionally equivalent to relevant questions. Some questions (Did you kill...?) may cause excessive emotional response in the subjects (as noticed by Reid and Backster), which would result in considerable changes in physiological parameters (23). The doubts are particularly valid when the subject is a relative of the missing person. The technique which in such cases may increase the accuracy of a polygraph examination is the SPOT. Here, questions on disposing of the body may be concealed in the wording of questions that concern for example an object that the missing person had on them or an item of their clothing.

J.A. Matte wrote: 'POT and the Probing (Searching) Peak of Tension Tests (...) have been widely used by field forensic psychophysiologists since the 1930s' (18). This is confirmed in press reports: the SPOT technique was used long ago; in 1929, L. Keller used several tests of the type (including one with a map) in the case of murder of J.E. Bassett (16). Despite widespread use of the SPOT for over 80 years in various countries, the number of publications devoted to it (in comparison with the number of articles on other techniques) is small if not insignificant. There are reports on individual cases, while field study analysis and descriptions of experimental research are lacking.

\section{Effects of SPOT application presented in relevant literature}

From the cases of SPOT application reported in the literature we might conclude that SPOT advantage consists in discovering objects connected with the investigated event. Spectacular effects of the use of SPOT tests in detecting and proving homicide in cases initially qualified as concerning missing persons were discussed by Owen M. Wilkerson (29). One of these cases dealt with a subject suspected of abducting two women in 1977 . The man denied the charges and the allegations that he had any knowledge of the incident. The suspect and his attorney agreed to a polygraph examination concerning the location of the missing women, and making use of a 'search peak of tension' technique. It was agreed that the examiner would ask only about geographic locations and the suspect would answer 'no'. A few SPOT tests were used during the examination, including a test with a map. Each test was repeated. Names of a handful of counties were mentioned in the first test. The subject reacted to one of them and in the subsequent tests he reacted to one of the sectors of the map of 
the county shown to him. The area was searched and the bodies of the women were found. The suspect was sentenced to death (29). The case is quoted by N. Ansley, who also describes another one (2). Two examples are quoted by Matte; one is concerned with money stolen in an office, while the other with searching for unknown accomplices (18). S. Abrams describes examination of a man whose wife went missing. It actually had killed her, and the body was found at a location he reacted to in the searching peak of tension test (1). None of the quoted examples was illustrated by test charts.

Several examples of test application in practice were provided by Lithuanian authors, V. Saldziunas and A. Kovalenko:

- disappearance of a person: the suspect confessed to a murder and showed the place where the body was hidden (24)

- successful use of the test with a map (sectors) in the case of a stolen car (25).

The authors quote examples and SPOT charts (with interpretation) from their own practice (26).

The number of publications concerning experiments using SPOT is also low. A relatively highest number has been published in Japanese, for which reason they are not easily available, but the effects obtained are significant in the context of other authors' views on the technique, and are discussed further in the article.

In the mid-1970s, M. Dufek and J. Widacki with his Polish team tested the accuracy of the test in terms of determining the place where a subject hid an object (5). Thirty men participated in the experiment, each of whom had 9 options to hide an object. If the subject successfully 'cheated' the expert, he was allowed to keep the object. The test was conducted five times (also in the SAT version, Yes-Test). Using polygraph charts, the expert correctly indicated the place where the object was hidden in the case of 22 men $(73.3 \%)$, in the case of further 7, the expert indicated it together with another place and only one man did not display physiological reactions to the place where the object was actually hidden. The authors argue that in real life cases the accuracy of the test would even have been greater, as emotional activation of the subjects in such cases is greater than during an experiment.

The discrepancy between a small number of publications concerning the technique and a long period of its application raises many questions. The most important one concerns the actual frequency of the use of the technique: how often has the use of SPOT chart analysis resulted in finding an object (or a body) in the place to which the subject reacted? If this hardly ever happens, are SPOT tests useful for investigation in any other manner? 
Other, more detailed questions also emerge; are results of a Comparison Questions Test, which, as has been mentioned above, provide the grounds for the decision to use the SPOT, always accurate? Obviously, accuracy of some versions of CQT tests is very high, but an error to the disadvantage of an innocent person in CQT tests cannot be ruled out (excessive reactions to relevant questions may occur, which is probable when the missing person's relatives are examined) as well as an error to the advantage of the actual perpetrator (if the perpetrator is examined a long time after the event had taken place or if he or she is a mentally resistant sociopath). Should the SPOT be carried out despite lack of reaction to relevant questions in the CQT test? Can we expect a contradiction between the conclusions resulting from the analyses of the CQT and SPOT?

\section{General remarks concerning the author's own practice}

I have used the tests relatively rarely, mainly in homicide cases. I first carried out Control Questions Test in Reid's version (23), followed by two SPOT tracings, and having asked all the questions in the second tracing, I repeated the options that caused the strongest reactions. Sometimes, when tracings of two parameters changed considerably after one of the questions, I regarded it sufficient and resigned from repeating the SPOT test. It was a mistake, as the review of the cases proves that I failed to appreciate another advantage, namely a greater probability of confession of the perpetrator resulting from the repeated administration of the test.

I used Lafayette equipment: model 76058 and model $761-96 \mathrm{~S}^{*} \mathrm{C}$. The analysis of the charts was carried out visually, resulting in a holistic assessment.

A statistical analysis of these cases did not make much sense due to major differences between them: the time between the event and polygraph examination (from several weeks to four years), and legal and psychological circumstances of the subjects (some were arrested, other had the status of a witness). ${ }^{1}$ Therefore, I will use the case study method, which prevents categorical conclusions. My remarks should be treated as hypotheses; some - concerning test structure, formulation of questions and diagnostic significance of the SPOT test as compared with the CQT test - may be attractive for other experts and may become an incentive for sharing their observations.

\footnotetext{
1 Most frequently this was caused by the fact that much time passed between the event and polygraph examination. The delay was caused by objective (related to the event and the person) and subjective factors, i.e. inappropriate use of polygraph expertise in Poland by the police and prosecution (polygraph examination is sometimes commissioned several months after the suspect is arrested).
} 
Only in one case was the object found in the place which the subject reacted to in a SPOT test. This indirectly explains the low number of publications confirming the basic effect of the use of the technique. However, it would be a mistake to conclude that it is practically useless. SPOT tests contribute another, considerable advantage to the investigative practice, i.e. a confession of the suspect. This is decisively the main advantage, and this is what the legal significance of the SPOT test hinges on. The investigators also found that SPOT test results were very useful when co-perpetrators or accomplices were concerned. In my practice I have experienced frequent cases when the subjects confessed, revealed the place where they hid or disposed of the objects, yet they were not found there. A question arises therefore: what decision is a police officer or a prosecutor supposed to make if the subject displays a reaction to the name of a place, but the object is not found there? The answer is even more urgent if the suspect revokes the confession before the court. This is not a purely rhetoric question, as such cases have occurred in my practice; there have even been cases when the subjects confessed, indicated the place where they had disposed of the object, but the objects were not found.

In a dozen of cases I performed SPOT tests despite absence of reaction in the subjects to relevant questions in the Control Questions Test (serious circumstantial evidence incriminated the subjects, while the examination was carried out more than a year after the event). These people did not display any reactions to any SPOT test questions, while their emotional activation diminished. This reinforced the conclusion resulting from the analysis of CQT tracings, which was important due to serious circumstantial evidence incriminating the subjects in question. I ruled out their participation in the investigated events, which was later confirmed by other evidence. Thus, in effect they were SPOT tracings of innocent people, while the literature remains silent as to the use of these tests in this category of subjects. The tracings may be useful in determining the degree to which the problem formulated in SPOT test questions activates emotionally the innocent people and perpetrators.

There have been isolated cases where the opinion (diagnosis?) based on their CQT charts would have been false; in one the subject's perpetration was to be ruled out (in his case reactions to control questions predominated) yet he was the instigator of a murder. Decisive for the accurate diagnosis was the modification of the CQT technique (extra relevant question no. 11), additional R-I test and precisely the SPOT test (the chart will be discussed in the following publication). In another case, a man who was a witness and probably assisted in hiding the body was diagnosed as the murderer, as there were considerable reactions to relevant questions in three CQT charts (13). 
I made other mistakes in the use of the technique; they are worth mentioning because they illustrate problems involved in its application, and indirectly indicate the reasons for cautious approach in assessing its evidential value. Their discussion will allow other experts to avoid similar mistakes.

\section{Recommendations concerning structure and application of SPOT tests}

It seems necessary to summarise the views on the application of the SPOT technique, as they coincide in some respects and are divergent in others. The authors writing about this test agree about one basic issue - it should be used after CQT as supplementary testing. They do not differ on such issues as placing the most probable options in the middle of the test and repeating the test (even three times). They also agree on the principles of tracing analysis - it should be assessed which question causes repeatable changes in at least two charts (18). The APA recommends that if the examinee displayed physiological responses at the same question on at least two of the tree POT or SPOT charts collected, the examiner must conclude that there were significant responses' (6). According to the same recommendations, the numerical analysis of the charts is not carried out. Harrelson recommends to 'watch the Galvo tracing. It can be the most important indicator in this type of the test' (7).

Harrelson's observations concerning the significance of the galvo tracing are confirmed in research by the Japanese authors (1976) looking for objective methods of chart analysis. They decided that the visual method was too subjective (22) having analysed the charts of 40 people examined in authentic cases (theft, arson, robbery). Breathing, GSR, and pulse were recorded. Three charts from the stimulation test carried out in each case were selected for the analysis. The stimulation test had the subject select one of six two-digit numbers (from 20 to 70) and write it down. When the expert, who did not know the number, asked about it, the subject gave a negative answer. The test was carried out three times and the sequence of the questions was changed. The authors of the article analysed the tracings of individual parameters, trying to determine the usefulness of each of them for guessing the number selected by the subject. For this purpose they ranked the questions in terms of extent of reactions seen in these parameters. On the basis of the breathing analysis, the selected number was successfully determined in $46 \%$ cases, while the analysis of the galvo tracing resulted in $72 \%$ success rate. The pulse rate of most subjects exceeded 100 cycles per minute. ${ }^{2}$ It is interesting that the pulse rate was much higher than the

\footnotetext{
2 All the subjects were perpetrators, the group of the subjects did not include the 'innocent'; therefore, the expert did not compare the tracings of the 'perpetrators' with those of the 'innocent'.
} 
rest rate, but the assessment of this parameter would require a comparison with the charts of the 'not guilty' subjects, while here everyone was a perpetrator.

There are considerable differences between Harrelson's recommendations from 1964 and what more contemporary authors recommend. In his publication, Harrelson adopted the following assumptions for this test: 'Where the crucial possibility is included in a list, the creation of padding and the running of the test twice without stopping makes it possible to build the subject to a psychological peak at, or just prior to, the crucial question and afford relief from this peak at, or after, the crucial question, providing the subject knows the exact sequence in which the questions are going to be asked, since he must know where he will have to lie or make an admission against interest' (7). Therefore, the content of the questions and their sequence should be discussed with the subject and when rerunning the test, their sequence should not be changed: 'Never alter the consecutive order of questions. Subject must know and anticipate the position of the crucial question' (7). Harrelson also highlights that: 'questions are never vague or indefinite' (7).

Ambiguity or overlapping of the question content may cause a subject's reaction to more than one question, which will result in a diagnostic problem. An example of such an error can be found in the two SPOT tests I carried out with a subject suspected of a rape and murder of a young woman in summer 1978. While, after the examination, the man confessed and was subsequently convicted, his reactions in the test were ambiguous, precisely because of wrong assumptions adopted when constructing the two tests and the inappropriate wording of the questions. ${ }^{3}$

The event was initially treated as the case of a person gone missing. The body was found three weeks after the murder in a ditch filled with water, covered with a bundle of dry maize. The cause of death was difficult to determine: the victim had sustained injuries to her head, but she might as well have died after her body had been thrown into the water. The body was naked and no clothing was found in the vicinity. There was also no jewellery, while the victim's friends testified that she had always worn five rings, earrings, and two pendants. The subject was examined two days after the body was found. He denied the charges of murder, there were no witnesses, no traces, and no material evidence. Thus a polygraph examination potentially had a great significance. Apart from a CQT test, I also carried out two SPOT tests: one concerned the manner of hiding or destroying the clothes, while the other - the manner of hiding the jewellery. If the suspect was the murderer, he should know the place where the objects had been hidden, he should react to its name and the search of the place would have resulted in finding the clothes and/or jewellery. The results

\footnotetext{
3 Provincial Court in Wrocław III K 117/79.
} 
of those tests could contribute to obtaining material evidence. Each SPOT test was carried out twice.

The first SPOT concerned the place where the clothes had been hidden or how they had been destroyed. Hiding or destroying them was not difficult, because the crime was committed in summer and victim did not wear much (a dress, panties, and a bra).

The test questions were as follows:

1. Did you bury the woman's clothes?

2. Did you incinerate the woman's clothes?

3. Did you hide the woman's clothes inside a building?

4. Did you hide the woman's clothes in the fields?

5. Did you throw the woman's clothes into a river or a septic tank?

6. Did you hide the woman's clothes in another way?

When the test was administered for the first time, the relatively greatest changes were caused by question 5 , therefore, when the test was conducted for the second time, it was repeated four times.

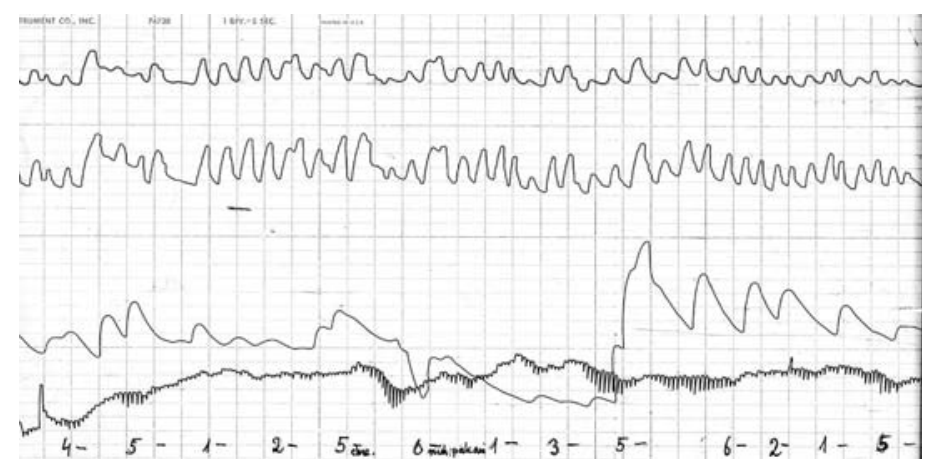

Fig. 1. The second chart of the SPOT test concerning the possible way of hiding or destroying the clothes.The subject's breathing was irregular, of varying depth, pulse rate: 90 , diastolic pressure was very high (small amplitude), and considerable changes in the galvo tracing. Breath tracing may be concluded as resulting from great general activation or an attempt at distorting the tracing. Shallow breathing could also cause an increase of diastolic pressure and changes in the galvo tracing. Relatively greatest changes are caused by question 5 (throwing the object into a river or a septic tank), but other question are also followed by changes. 
The SPOT test concerning the way of disposing of the jewellery included the following questions:

1. Did you sell the woman's jewellery?

2. Did you bury the woman's jewellery?

3. Did you give the woman's jewellery to someone to keep?

4. Did you throw away the woman's jewellery?

5. Did you hide the woman's jewellery in another place?

There were no unambiguous reactions to any of test question in the first chart.

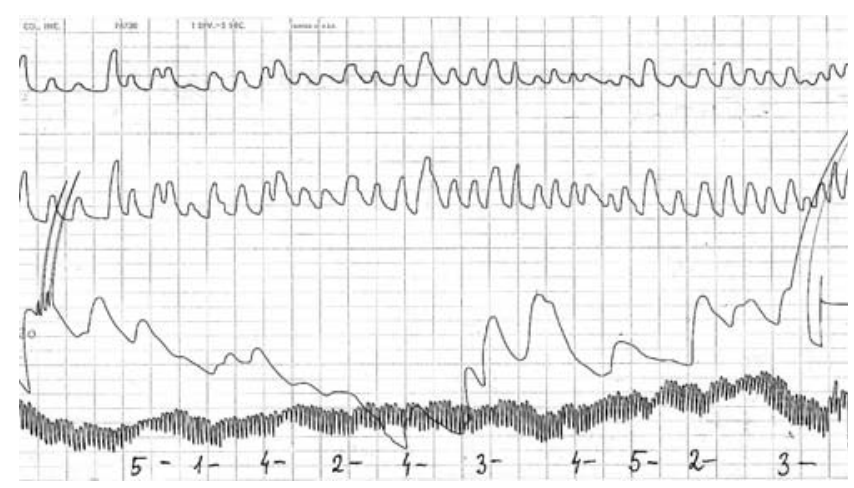

Fig. 2. The second chart of the test concerning possible ways of disposing of the victim's jewellery. Pulse rate: 90 . Physiological parameters indicate a considerable degree of activation but lower than in the previous test. The reactions are ambiguous; no particular question causing the strongest emotions can be indicated.

The subject confessed his guilt to a police officer two months after the examination. He said that he had scattered the woman's clothes in the fields. He indicated the places during the visit to the scene of the crime, but the clothes were not found. However, it is not certain whether he told the truth about what he had done with the clothes. In the first test chart, there was no reaction to question 4 concerning just this possibility (hiding in the fields), while there were changes following other questions, and especially question 5, therefore it was repeated four times in the second chart. When the test was repeated, question 4 was treated as a padding question. Despite confessing to the rape and murder, the perpetrator did not want to disclose what he had done with the jewellery. Comparison of both test charts reveals that the issue of hiding the clothes activated the subject to a considerably greater degree than the issue of the jewellery (if it is assumed that he did not distort the SPOT tracings concerning the clothes by shallowing his breath). 
It is obvious that the structure of the tests (hiding the clothes, dealing with the jewellery) was wrong, because it was assumed that the subject had dealt with all the objects from each group (clothes, jewellery) in the same way, while he could have sold one ring, given another away as a gift, and hidden the rest somewhere. He could have dealt with the clothes in a similar way, even though this is not very probable due to their insignificant value. It cannot be ruled out that he told the truth talking about the clothes, as they may have been destroyed by the machines working in the fields: there was a gap of three months between the murder and the confession. The test concerning the jewellery should have focused on each item separately. The other test should have concentrated on the dress only, not referring to the collective notion of 'clothes'. The latter would have been justified if the test had aimed at the assessment of the general level of the subject's emotional activation and not at finding objects.

Lithuanian authors highlight the difficulties in separating the question content in a SPOT test (27).

The greatest discrepancy in literature concerns the number and sequence of questions and the change of the sequence when the test is repeated. According to Harrelson (7) and similarly to Nakayama (19), a test should include 5 items, while Ansley recommends 7, and Matter - 9. The American Polygraph Association recommends yet another solution, which is discussed below (6).

As I have mentioned above, everyone recommends that the most probable items are placed in the middle of the test. Ansley's view is representative in this matter: 'The most probable item should be in the middle of the list during the first of three presentations. The last probable item should be at the beginning of the list during the first of three presentations' (3). J.A. Matte puts forward a similar recommendation: "The choices are listed in the order of least likely, most likely, least likely, finally followed by an all inconclusive question such as "any other place I haven't mentioned?"' (18).

The certain doubts that arise here probably constitute one of the reasons why the evidential value of SPOT tests is assessed so cautiously: an innocent person may assess the item considered the most probable by the expert in the manner expected of the perpetrator. This person may have general knowledge about the event being tested and his or her own conjectures as to the motive, perpetrator, and his or her way of operating. The subject's hypothesis may coincide with that of the investigator, while mental processes connected with the hypothesis may cause an emotional reaction to a particular item. An opposite situation may arise: the actual perpetrator may distort the tracing in a SPOT test, thus hindering the identification of the appropriate item. A diagnostic problem arises: what should the expert's conclusion be? In my opinion, 
the solution lies in the assessment of the degree of emotional inactivation caused by the problem formulated in the test, which proves that the subject conceals a detail of the event, and not in the assessment whether a reaction to one item may be seen.

Apart from Harrelson, the remaining authors recommend that the order of questions is changed while repeating the test. N. Ansley writes 'The order should be varied with each presentation. The order of items may be announced or posted. The items in the list should be discussed in detail. When maps or diagrams are used, they must have clearly marked boundaries, numbers, letters, and names for each area' (3). According to APA recommendations, the third test should be carried out with the reverse order of questions (6). Harrelson did not recommend the use of a question about 'other options', because the perpetrator will realise how little the investigators know, which will decrease his or her fear of exposure and thus the reactions during the test. Among contemporary authors only Nakayama is against such a question, but for a reason different than Harrelson: 'Some examiners include a catchall question, such as "another place than mentioned" at the end of the sequence. This is very different from the other questions and the reaction to the question is not meaningful' (19). The remaining authors recommend its use. J.A. Matte: 'The choices are (...) finally followed by an all-inconclusive question such as "any other place I haven't mentioned?"' (18), and N. Ansley: 'Use a question about other possibilities as the last item on each chart' (3).

In his recommendations concerning the constant order of questions and avoiding the question about 'other possibilities' L. Harrelson adopts an assumption that the investigator and expert are not mistaken, i.e. that their knowledge on the most probable item is real. Seemingly, the assumption is correct, but if this were the case, why conduct the test? Would it not be better to search the two places if the body or objects were hidden there? In practice, it is not the case; the investigator and polygrapher may only formulate hypotheses, not being aware of the actual manner of operation (or a place), which is substantiated by the following case:

In 1995, two drunks were battered to death (13). According to the profiler, there must have been two attackers, because two men would have been able to defend themselves against one. The skin of the victims' faces was cut and skull bones were broken, which proved that the perpetrators had used an object with sharp edges. No such object was found at the scene of the crime and in its vicinity, which prompted the conclusion that the perpetrators had taken it away with them. After eight months, the police received information that the battery might have been committed by a small group of very young men. All agreed to a polygraph examination. The examination, carried out in the CQT technique, ruled out their participation, except for one of them. I examined him, using the SPOT test, to determine what the perpetrator used to hit the victims. The test named various objects that could have been used. 
Test questions were:

1. Did the perpetrator hit with a crowbar?

2. Did the perpetrator hit with a stool?

3. Did the perpetrator hit with a tyre lever?

4. Did the perpetrator hit with a stick?

5. Did the perpetrator hit with a poker?

6. Did the perpetrator hit with a thick cable?

7. Did the perpetrator hit with another wooden object?

8. Did the perpetrator hit with another metal object?

9. Did the perpetrator hit with another object?

In the test, the subject reacted to question 9 (another object). He refused to have the test repeated and terminated the examination. After the examination, he confessed to a police officer and said that he had had no accomplice. He stated that he had been first attacked by the two men, but because they had been drunk, he had easily defended himself, hitting them with his fists. When they fell down, he kicked them on the heads (he had big, heavy boots, whose soles had metal fittings on the edges).

This example proves that the question about 'other possibilities' is indispensable, because it is very hard to take all possible manners of the perpetrator's behaviour into consideration. It seemed that the test questions covered all possible objects, yet they did not include kicking, as sole edges hardly ever have sharp edges.

The SPOT test questions are worded on the basis of the traces, and professional and life experiences of the investigator and the expert. Practice proves that the actual manner of perpetrator's operation may by missed out and sometimes it is difficult to meet Ansley's requirement that: 'In constructing a Searching Peak of Tension test, sometimes called a SPOT test, the examiner was to cover all possibilities, and padding questions which were outside the realm of possibility were to be at the beginning and end of the list, with two at the end if possible' (2).

A risk of committing such a mistake is present when trying to determine an unknown accomplice, which is substantiated by the case of a murder committed by a police officer in 1994 (10). Some evidence unambiguously indicated the perpetrator, who however did not confess, and did not agree to a polygraph examination. However, it was necessary to determine who had helped the murderer to place the body in a car and take it away. A few people, including the officer's colleagues, were subjected to the polygraph examination. A CQT test, Situational Sequencing Test (STS), and a SPOT test with the names of more than ten acquaintances of the perpetrator and the subject's name were performed. The CQT and STS charts ruled out personal participation of these people in transporting the body, while in the SPOT test they reacted only to their own names. The last but one of the subjects stated after the SPOT 
test that the murderer's wife was the accomplice. The investigator did not take her participation into consideration, because the victim weighed almost $100 \mathrm{~kg}$, and the perpetrator was drunk. The accomplice had to be strong, while the wife was only 160 $\mathrm{cm}$ tall and weighed $50 \mathrm{~kg}$. The test was supplemented with the woman's name and the last potential accomplice displayed a clear reaction to it, while being examined, and showed no reaction to his own name. Test charts are presented elsewhere (10).

The APA seems to propose an optimal solution concerning the order and content of questions (6). An example of the test:

'Regarding the location of that property is located in:

Padding question Geneva?

Padding question London?

Key choice area A?

Key choice area B?

Key choice area C?

Key choice area D?

Coverall an area not mentioned?

Padding question Frankfurt?

Padding question Milan?'

In this version of the test, the question about 'other possibilities' is treated as an essential alternative, while placing two padding questions at the end solves the problem when the test is repeated with a changed order of questions. The number of 5 items seems minimal, especially when accomplices are concerned. I believe that there may be more questions, it is more crucial that they cover all possibilities. The test should be repeated three times, featuring the reverse order of questions in the last instance. All questions are worded to elicit a 'no' as the answer. While all the authors agree that the subject should answer the test questions, experiments carried out in Japan (H. Okhawa) proved that in this test subjects displayed reactions also when it was conducted in the SAT version.

Histasugi Okhawa discusses experimental research of 40 people carried out in 1963 (21). Each person took one of four objects in secret from the expert. The expert's task was to discover which object had been taken away, for which purpose he carried out the same Test POT-B several times. The subject gave answers in the negative (the answer to one of the questions had to be false). The test was conducted twice and then the same test was repeated twice but the subject remained silent, not answering the questions. On the basis of the tracings, the expert decided which object had been taken by the subject. Subsequently, the third test was carried out, when the subject gave truthful answers. When the subjects gave negative answers to all the questions, in $90.2 \%$ of the subjects the tracings displayed changes after one of the questions, 
which proved that it was the critical question. In the 'silent answers' version such changes to one question were displayed by $87.5 \%$ of the subjects, thus the difference is slight. ${ }^{4}$ The author of the article does not reveal what parameters he recorded. The subjects did not include 'innocent' people, therefore the expert was unable to compare the tracings of the 'perpetrators' with those of the 'innocents'. The examination in question proves that it is the question's content and not the negative answer, i.e. the subject's lie, that causes an emotional reaction.

\section{Legal significance of SPOT tests in practice}

As I have mentioned above, only in one case in my experience has the wanted object been found in the place the subject reacted to.

It was a case of a murder of a woman in 1982 (13). The subject was a man who presumed to have committed the crime in his flat (while his wife and son were absent) and have hidden somewhere the duvet with traces of victim's blood (his wife claimed that one of the duvets was missing). His status was that of a witness, and the examination was carried out six months after the murder had been committed. His flat had previously been searched twice in vain, therefore he did not have to fear that the object would be found. He reacted symptomatically to a relevant question in the CQT test and in the SPOT test the displayed a distinct reaction in blood pressure and galvo tracings to question 4 .

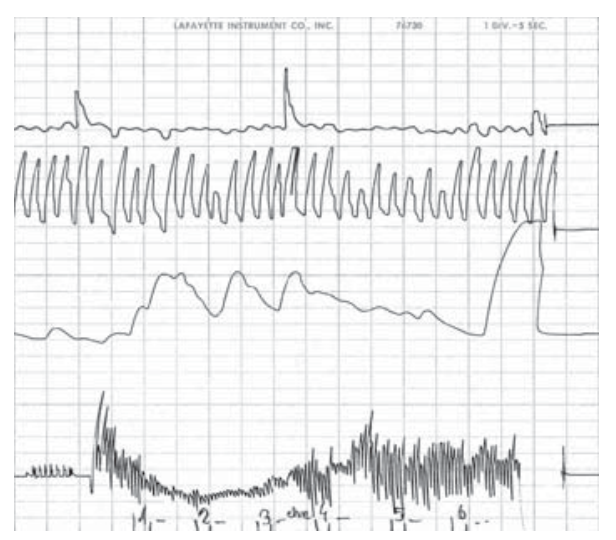

Fig. 3. The chart of the SPOT test: reactions are present in all the parameters until question 4 and then they return to normal, which proves that the subject's emotions decrease.

\footnotetext{
4 There is no information on the degree of general activation of the subjects; it cannot have been high, because the expert examined his colleagues. It is interesting that $10 \%$ of the subjects did not display any significant changes.
} 
After the polygraph examination, the subject confessed and showed the place where the woman's clothes had been hidden. ${ }^{5}$ It was a place whose name he had reacted to in the test.

There have been more cases when the subject reacted to one of the options named in the SPOT test, but the objects were not found in the place indicated, mainly because considerable amount of time had passed between the examination and the polygraph examination (the objects may have disintegrated naturally or may have been taken away by strangers)

This type of situation is illustrated by an examination of a subject suspected of murdering a man in 1978. ${ }^{6}$ A broken knife blade was found in the victim's body, and the handle was missing. Several witnesses had seen such a knife in the possession of the suspect shortly before the event, but he denied it. In the CQT, the subject displayed considerable and repeatable physiological changes after relevant questions. The SPOT focused on what had happened to the knife's handle. According to police officers, the most probable option was that it had been thrown into a sewer (question 6). If this had proven true, the sewers would have been searched. The test provided for seven options, and additionally included a question from the CQT test (no. 8): Did you have the knife on the day of the murder?

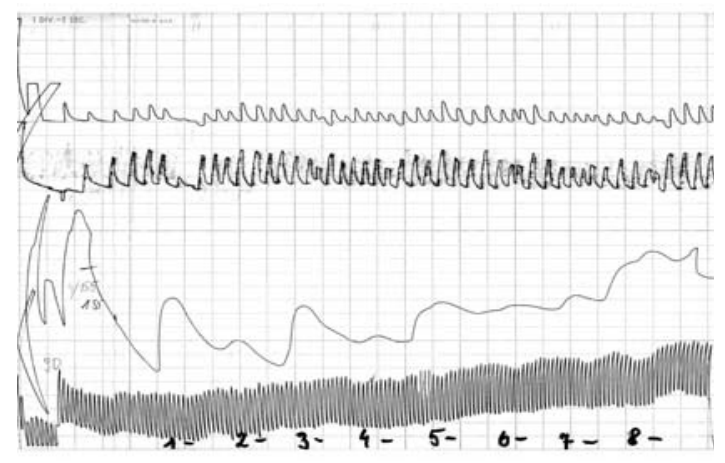

Fig. 4. SPOT chart concerning the manner of disposing of the knife's handle. The suspect did not display the expected reaction to question 6 . The greatest changes (galvo and breathing tracings) were caused by question 3 - thrown into a dustbin.

\footnotetext{
5 The perpetrator died in 1986 because of a brain tumour, three and a half years after polygraph examination. If the polygraph examination had used magnetic resonance or brain wave analyser, the instruments would have been alleged to have caused the brain cancer.

${ }^{6}$ District Court, Wrocław Śródmieście III K 633/78.
} 
A few weeks after the polygraph examination, the subject confessed. He explained that he had thrown the handle into a dustbin. No one looked for it there, because a few weeks had passed since the murder and in the meantime the dustbins had been emptied several times. The court sentenced the accused but recognised that he had acted in self-defence. It is worth noting that absence of a reaction to question 6 (thrown into the sewer) was important for the investigation, because the idea to search the sewers was abandoned and there were more than a dozen of them in the vicinity of the crime scene.

My practical experience suggests marginal significance of the SPOT tests, highlighted in the literature as all-important, because they lead to finding an object in the place which the subject repeatedly reacted to. If this was the only effect of application of the technique, it would have to be considered useless. Yet, such a conclusion would be wrong as my experience also proves that it frequently offers another advantage, mentioned by Lykken: most subjects confess after the test. It is important to note that a confession was relatively more frequent than in the cases when only the CQT or a combination of CQT and POT tests were used.

The Japanese authors report a great impact of the SPOT tests on the confession of the subjects. In 1963-64 Hikita and Suzuki examined 116 convicts, who had earlier confessed to such crimes as theft, blackmail, and rape (8). Hikita and Suzuku conducted polygraph examinations to find out whether there were any other offences that the subjects had not confessed to (i.e. whether they had not concealed them). The examination was carried out in the presence of police officers conducting investigations. If the subject had confessed to another offence in the presence of a police officer, his or her confession would have become evidence for the court. ${ }^{7}$ First, a CQT test was carried out: the subject was to listen to the questions and answer them truthfully. It was followed by a stimulation test with the use of playing cards. All this was followed by two CQT tests. If the CQT charts did not show any reactions on the part of the subject to the relevant questions, subsequent tests were abandoned. If the reaction, however, did occur, subsequent tests were conducted. The test included 15 questions about various crimes and offences (various types of theft, bodily harm, blackmail, rape, burglary, document forgery, arson). If there were no reactions to these questions, subsequent tests were abandoned. If there was a reaction, e.g. to the question about a theft, another test, consisting of 21 questions about various objects (a bicycle, car, money, ring) was conducted. The third test included 20 questions about a geographically determined place where the offence was committed.

\footnotetext{
7 It is highly doubtful whether this procedure could be applied in many countries nowadays, as it is deceitful and forcing self-accusation.
} 
The fourth test (11 questions) concerned the crime scene, which this time was defined by a name (a shop, school, park, flat). The results were as follows:

1) reactions were displayed by 83 people, who confessed to committing another crime ( $71.55 \%$ of the subjects); 5 people displayed distinct reactions, but they did not confess

2 ) in the case of 28 people (24.14\%), it was concluded that they had not concealed the fact of having committed a crime.

Hikita repeated this examination in $1965-67$ on a group of 254 people. Reactions were displayed by $77.56 \%$ of the subjects, who either confessed or their crime was proven in another way (9).

It is significant that most of the accused revoked their confession in court, yet courts sentenced them anyway (considering the change of testimony as not credible; also quite frequently other evidence confirming the perpetration had been acquired). ${ }^{8}$ A serious diagnostic and legal problem arises here, resulting from the situation when the object is not found at the place which the subject reacted to, the charge has been filed in the meantime, and the accused (who is actually the perpetrator) revokes his or her confession and quotes the result of the SPOT test before the court as a proof of his or her innocence. The accused may even go further: if the object has not been found despite the occurrence of a physiological reaction to the name of the place, a conclusion must be inferred that the reactions are coincidental, which is also true for CQT charts. In such a situation, in the opinion of the defence counsel, the result of the CQT test should be dismissed as valid evidence.

Such arguments have not been raised yet, but neither the defendants nor the defence knew the literature on the polygraph. In the meantime, the knowledge of testing techniques has become quite widespread and if a defendant or a defence counsel become familiar with Lykken's view, such arguments might be raised. It would be sensible to consider a change of the paradigm of the diagnostic significance of test tracings. I believe that an expert's appraisal should primarily be concerned with the degree of the subject's emotional activation by the issues to which the SPOT test is devoted (taking into consideration its consecutive charts and with reference to the CQT test). SPOT charts should be one of the premises in the final appraisal of the result of polygraph examination in correlation with the reactions to relevant questions in the CQT test. Finding an object in a place to which a considerable and repeatable reaction occurred is an additional and not fundamental advantage of the application of the SPOT test.

\footnotetext{
8 There are substantial differences between evidential significance of confession of the accused in the US and Poland.
} 


\section{Emotional significance of SPOT tests}

My practical experience proves that SPOT tests cause considerable emotions in the subjects who transpired to be perpetrators, while the degree of their general psychophysiological activation displayed an increasing tendency when SPOT tests were repeated. I estimate that it was even higher in SPOT than in CQT tests, which is substantiated by the following parameters; higher diastolic pressure, more irregular breathing, frequent changes in the galvo tracing.

This remark is substantiated by a case of a young man examined in the case of a murder of a 15 -year-old girl in 2006. ${ }^{9}$ The examination was conducted a year after the event. The subject had a status of a witness. Apart from a CQT test, I used a SPOT test, which included 8 questions about possible ways of handling the girl's backpack. Even though she had it with her on the day of the murder, it was not found on the body or in the vicinity. The test began with padding questions, marked as A; B; C, etc.

Test questions were as follows:

1. Following the event, was the backpack buried?

2. Following the event, was the backpack incinerated?

3. Following the event, was the backpack thrown into water (river, lake)?

4. Following the event, was the backpack hidden in a building?

5. Following the event, was the backpack hidden under tree branches?

6. Following the event, was the backpack thrown into a shrubbery?

7. Following the event, was the backpack hidden in another way?

8. Following the event, was the backpack destroyed in another way?

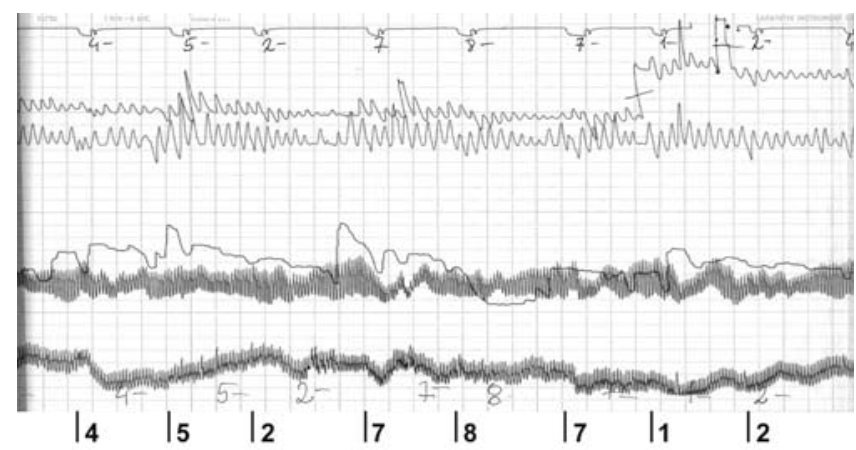

Fig. 5. First SPOT chart concerning the way of handling the murdered girl's backpack.

9 Prosecutor Office in Częstochowa V Ds. 41/06. 


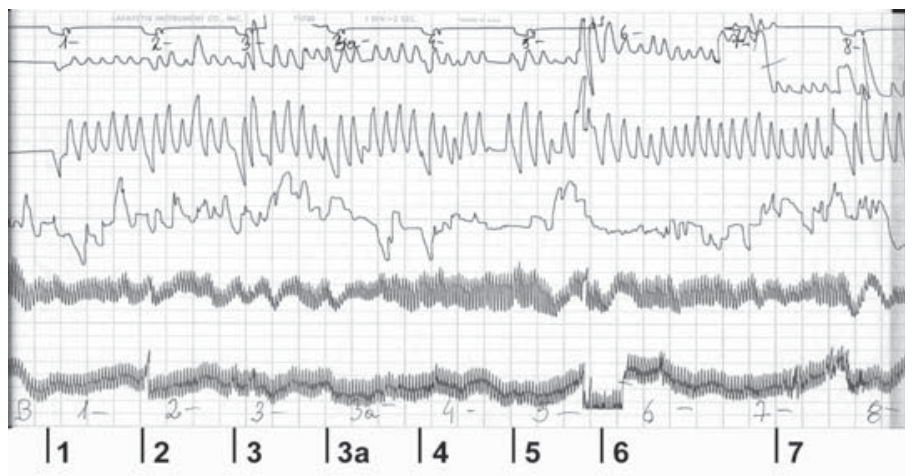

Fig. 6. Second SPOT chart concerning the way of handling the murdered girl's backpack.

The subject's considerable activation by the issue examined in the test is substantiated by the following physiological parameters: considerably quickened and irregular breathing, very frequent, however slight, tilting of the GSR pen (oscillation). The activation was so considerable that it is difficult to determine which question exactly caused the greatest reactions. In the second tracing the disturbances of breathing and galvo tracings were greater than in the first one. For a person unconnected with the girl's death, the problem formulated in the test would be emotionally neutral or only slightly activating. After the examination, the subject confessed to having strangled the girl. He said that he had thrown the backpack away in a forest, several dozen metres away from the body (which corresponds to question 6 in the SPOT test). The backpack was not found there, even though the place had been searched earlier during an inspection at the site of crime. It is difficult to conclude whether the suspect told the truth. Since he confessed to the murder, he was unlikely to have lied about a minor issue. Most likely, the backpack was found and taken away by a stranger. The suspect was convicted of murder.

The great effect which SPOT tests have on a murderer's emotions is confirmed by the tracings of a young man examined in the case of the disappearance of an eight-yearold girl in 2001 (12). The examination was carried out 5 months after the event. The main suspect was the girl's father, but he was eventually excluded, because in his case reactions to control questions predominated in the CQT test. The other subject had a status of a witness. He displayed strong and repeatable reactions to relevant question 8 'Did you hide the body somewhere?' The reactions to question 5 'Did you kill the girl?' were considerably smaller. Such reactions were surprising, considering the 
evidence acquired at that stage of the investigation. In this situation, I arranged for a SPOT test focused on the place and way of hiding the body. The test included the following 9 options:

1. Is the girl's body hidden in a residential building?

2. Is the girl's body hidden in a cowshed?

3. Is the girl's body hidden in a barn?

4. Is the girl's body hidden in a swamp?

5. Is the girl's body hidden in a meadow?

6 . Is the girl's body hidden in the forest?

7. Is the girl's body hidden in another place?

1a. Is the girl's body hidden in your house?

$1 \mathrm{~b}$.Is the girl's body hidden in the neighbours' house?

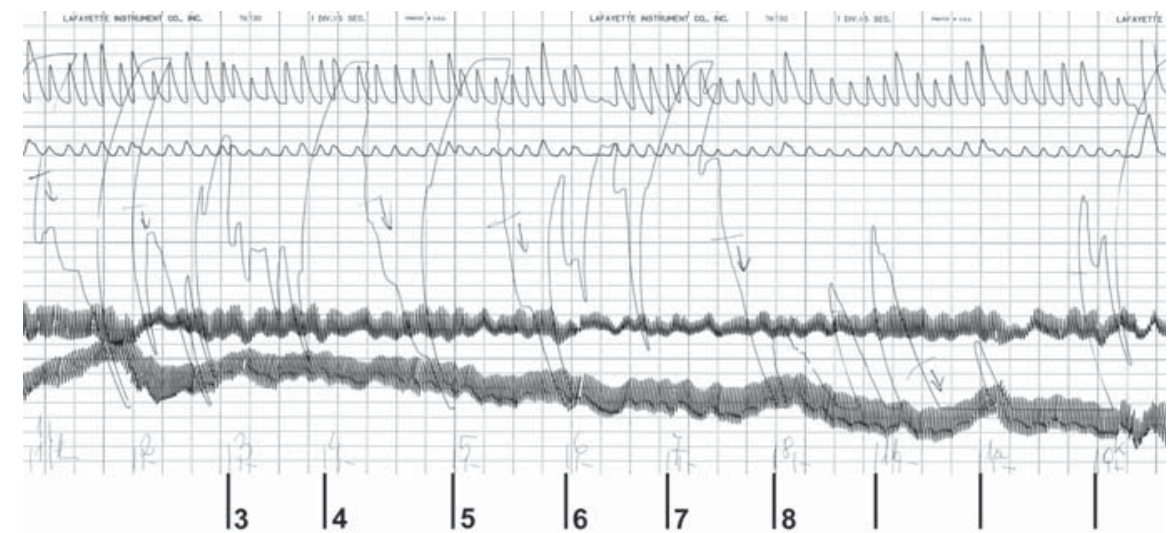

Fig. 7. SPOT test of the actual murderer of the girl. Galvanic skin resistance increases frequently and continuously, therefore the position of the GSR pen was corrected 7 times. Even though changes in galvo tracing make it difficult to determine the most relevant question, they are of the diagnostic value because they prove the existence and increase of general activation. This indicates that the examined person was activated with the issue set in the test. The changes in the blood pressure tracings do not change substantially. Breathing is shallower only following question no. 6 .

At the beginning of the SPOT test, the man went pale and remained so till the end of the test. After the test he became silent, and refused to talk and answer the questions. His mood was completely different from that at the beginning of the examination. He only said that several days before the event, without his parents' knowledge, he 
had been to the doctor, who diagnosed a serious heart disease (he was unable to give its precise name, but the description would suggest valvular incompetence or a defective development of a valve) and had told him that he would only live for a few more months. When asked why he had decided to see the doctor, he explained that he quickly tired and could not make any serious physical effort.

$\mathrm{He}$, nevertheless, confessed to the murder several months later during another interrogation, and testified that he had kept the girl's body in a few places and later incinerated it, which would explain strong reactions to question 8 in the CQT test and in the SPOT test about what had happened to the body. Long hair was found in one of the places, while a DNA examination confirmed similarity of its traits with mother's DNA. In court, the perpetrator revoked his confession, but he was nonetheless convicted.

This subject's refusal to undergo another SPOT test has in my experience been a behaviour frequently adopted by the subjects who later transpired to be the perpetrators. This confirms the claim that these tests have a great emotional impact on this category of subjects.

Some perpetrators have displayed distinct reactions during SPOT tests even a few years after an object had been disposed of and retrieving it was no longer a realistic option. This is substantiated by the examination of a subject suspected of murdering a man with a shotgun in 1991, which was carried out in 1995 (11). The prosecutor charged two men, who were subsequently arrested. The suspects agreed for polygraph examination. The prosecutor assumed that the first suspect had shot the victim, put the body into the boot of a car, transported it to another location, and left it there. He had also hidden the victim's bicycle. The man denied the charges and claimed that he did not know the other suspect. I administered a CQT test, a Situational Sequencing Test ('witness' and 'perpetrator' versions) and a SPOT test concerning the way of hiding the victim's bicycle (the victim had come to the forest on a bicycle). The problem formulated in the test was: 'What did you do with the victim's bicycle?', while the possible options were:

1) hid inside a building

2) threw into the water

3) dismantled

4) sold

5) hid in the forest

6) buried in the forest

7) buried in the field

8) hid in another way. 


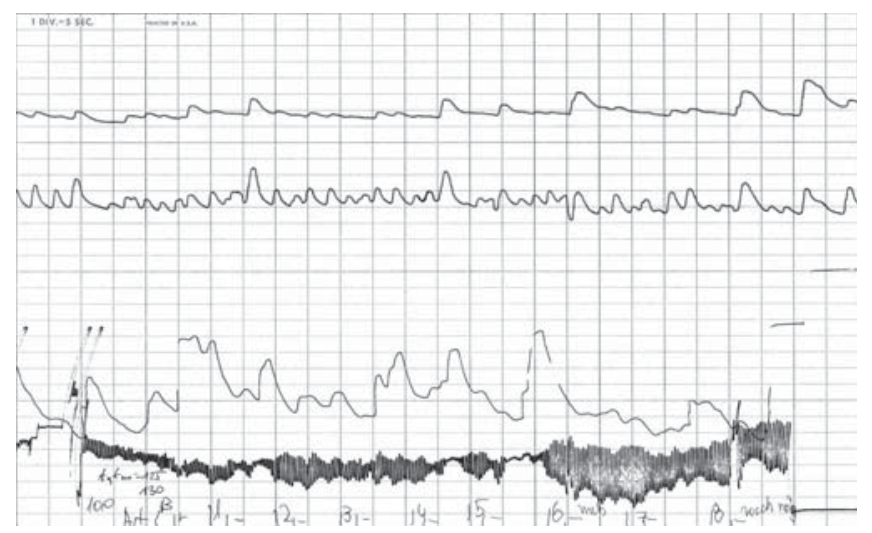

Fig. 8. The chart of the SPOT test 'What happened to the victim's bicycle?' from the examination of the main suspect.

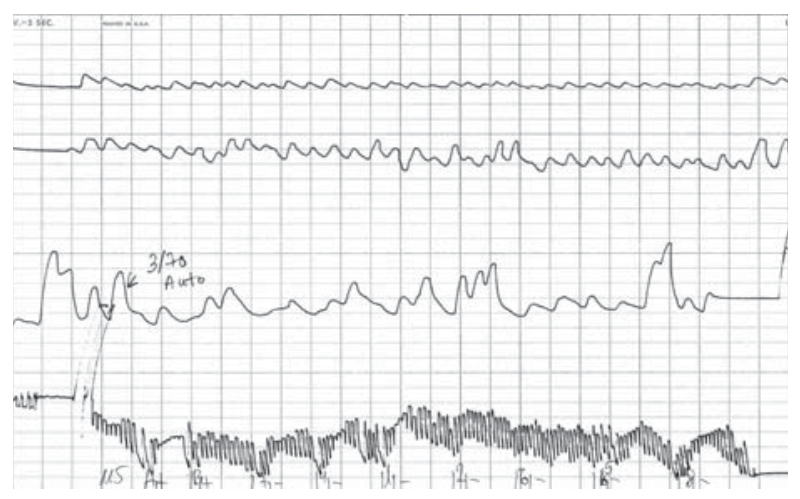

Fig. 9. Examination of the other suspect of murder. The SPOT test chart concerning the way of hiding the victim's bicycle. Reactions to the following questions may be seen: 1 (cardio), 2 (GSR), 5 (cardio) and 8 (GSR and cardio). The man suffered from cardiovascular condition - hypertension and arrhythmia. Pressure in the cuff had to be decreased.

A very distinct reaction to question 6 (GSR and decrease of diastolic pressure) proves that one of the options from the test (question 6) was actually true and that the suspect perceived the problem formulated in the test as a considerable threat. No one looked for the bicycle in the forest, as there was no realistic chance of finding it - four years had passed since the murder, and the forest covered a huge area. ${ }^{10}$

${ }^{10}$ If the bicycle was not buried, someone found it and took it home letting no one know. In Poland, many people pick mushrooms in forests, which is a specific pastime. The mushrooms are later eaten 
Comparison of this tracing with the tracing of the same SPOT test carried out with the other suspect proves that the reaction of the former to one of the questions was not coincidental.

Some parameters in this test indicate the subject's considerable activation (fast pulse rate, shallow and irregular breathing). Yet diastolic blood pressure tracing is completely different from that of the main suspect. The first suspect's distinct reaction in the SPOT test to one possibility should prompt the prosecutor to reject his argumentation that the reaction was coincidental or that the emotions were caused by the syndrome of the 'unjustly suspected'.

The main suspect was sentenced to imprisonment for committing murder. ${ }^{11}$ The other suspect was sentenced for imprisonment for failing to report the murder.

The examples above justify the hypothesis that SPOT tests greatly affect perpetrators' general activation, which is substantiated by such parameters as increased irregularity of breathing tracing and instability of the galvo tracing line when the test is repeated, greater changes of physiological parameters in comparison with CQT tests and stimulation test charts. This, however, is a subjective assessment, as they were analysed visually. Obviously, a computer polygraph would enable more precise measurement of physiological parameters and objective (numerical) assessment of the increase or decrease of emotional activation. It is still a hypothesis due to a small number of cases.

There are objective premises supporting the hypothesis proposed above. The most objective sign is the refusal of further participation in the examination, sometimes even after the first instance of administrating a SPOT test. This reaction occurred much more frequently than in the case of examinations carried out with other techniques. In one case, when these tests were used by Keeler, after consecutive tests with a map the suspect destroyed the polygraph, thus preventing an administration of the last test (16). Another fact proving a great effect of SPOT tests on the subjects' mind is the relatively frequent occurrence of confession (confirmed by judicial sentences).

Yet another objective confirmation of the hypothesis lies in the results of the experiments carried out in Japan in the early 1960s, mentioned earlier: reactions to one question in SPOT test in the 'silent answer' version were displayed by $87.5 \%$ of the subjects, and by $90.2 \%$ when they gave negative answers (21). The same conclu-

or preserved. Bodies buried in shallow forest graves are uncovered by animals and almost always found accidentally by mushroom pickers.

${ }^{11}$ In the justification of the sentence, the court listed four more murders, whose perpetrators had not been found and with which the subject could have been linked (serious conflicts with the victims). 
sion may be inferred from Dufek and Widacki's experiment mentioned above (5). The results are significant as they challenge the claims of the authors who identify polygraph examination with lie detection. Those subjects did not lie, because they did not say anything, while their emotions were caused by the issue formulated in the test.

An even more convincing argument for the hypothesis formulated above would be a comparison of the tracings of these people with those of the innocent, which will be presented in the next article.

The hypothesis of a considerable effect of SPOT tests on perpetrators' emotions should be interesting for psychologists, as it concerns behaviour after a crime was committed (disposing of the body or objects). Moreover, emotions were displayed by the subjects even though there was a slight chance or no chance of finding the object (plenty of time has passed in the meantime, the object was destroyed or taken away by strangers, the object did not display traces enabling identification of the perpetrator).

The following hypotheses may be proposed as to what the causes of the emotion could be:

a) Fear of the consequences of the object being retrieved, i.e. proving a serious crime and the ensuing punishment. This explanation is not convincing, because sometimes the test did not provide for an option which the perpetrator actually used (as long as he or she told the truth). Moreover, in most cases so much time passed between the event and the examination that the hidden (abandoned) object would have disintegrated.

b) The issue on which the test focused reminded the perpetrator of the event and the emotions that accompanied it. Are they caused by a memory or emotional trace?

c) Can the changes of the parameters result from mental and physical countermeasures? It is hardly probable, because some parameters may be changed (shallowing or slowing down the breathing), but increasing the pulse rate or blood pressure cannot be achieved at will.

Another conclusion is concerned with the diagnostic significance of SPOT tests. I am of an opinion that we should first of all assess the general degree of the subject's emotional activation in consecutive test charts and in comparison with other tests (CQT test, simulation test). Decrease of activation constitutes a premise for excluding the subject (NDI), while its increase - for considering him or her as a DI. When an expert devotes all his or her efforts to finding changes in the tracings following one of the test's questions, he or she may acquire an incorrect result; if the perpetrator hid the object in several places, two or more options may elicit reactions. 
The chance of finding the object (body) is practically non-existent. No such chance exists also if the perpetrator destroyed the object (e.g. incinerated it) or if places or methods not mentioned in the test were used. This would bring about an argument in favour of the defence of the accused if (after acquiring other evidence) a charge was filed. A similar problem arises if the subject reacts to one option, confesses, and even identifies the place, but the object is not found there and the accused revokes the confession in court. In my opinion it would be more appropriate if the expert stated that the problem to which the test is devoted activates the subject emotionally and that the activation tends to increase. Moreover, an expert opinion thus formulated would constitute a 'precaution' against the potential arguments of the accused mentioned above if the object is not found in the place to which he or she reacted. Another argument for such a sequence of the analysis is the ease with which the perpetrator may 'mask' the reaction to the right question by applying mental and physical countermeasures - it is sufficient to make breathing shallow or slower to cause changes in galvo tracing. However, it is more difficult to cause an increase in pulse rate or blood pressure at will. If the subject resorts to applying such measures, determining the place where the object is hidden or who the accomplice is will be impossible, but it will become a 'trap' for the perpetrator. Tracings of parameters, if they differ considerably from the physiological norm, will become one of the important premises of an accurate assessment.

Results of SPOT tests, consisting in the comparison of the degree of activation, may have a great diagnostic value for the general result of polygraph examination. They may considerably increase its accuracy, even if only as a screening test.

I must admit that in applying SPOT tests, I too often looked for a reaction to one question in the tracings of the parameters. Sometimes I resigned from repeating the test if a distinct change of two parameters was seen following one of the questions. This was a mistake, as I failed to appreciate the effect which the SPOT test has on the psyche and emotions of actual perpetrators, and especially the effect that the repetition of the test has on heightening of emotions. In result, the subjects did confess! If I had repeated the test, despite the subjects' distinct reactions, more would probably have confessed. The argument for repeating the test is justified not only by the will to determine whether the subject's reactions to one of the questions are not coincidental (i.e. whether they are repeatable), but by a greater probability of the perpetrator's confession. 


\section{References}

(1) Abrams S. (1989), The complete polygraph handbook, Lexington, Lexington Books.

(2) Ansley N. (1992), The History and Accuracy of Guilty Knowledge and Peak of Tension Tests, Polygraph, Vol. 21, No. 3.

(3) Ansley N. (1998), Question formulation, Polygraph, Vol. 27, No. 3.

(4) Backster C. (1969), Standardized polygraph examination notepack, San Diego, Backster Associates.

(5) Dufek M., Widacki J., Valkowa V. (1975), Eksperymentalne badania przydatności poligrafu do przeszukania pomieszczeń, Archiwum Medycyny Sadowej i Kryminologii, Vol. 25, No. 2.

(6) Federal Psychophysiological Detection of Deception Examiner Handbook (2011), Polygraph, Vol. 40, No 1. Special Edition.

(7) Harrelson L. (1964), The Polygraph. Interrogation, Chicago.

(8) Hikita Y., Suzuki A. (1965), Construction and Interviewing of Probing Peak of Tension Tests for Some Other Crime Suspected and Their Results. Research Materials, No. 35. Polygraph Reports, National Research Institute of Police Science.

(9) Hikita Y. (1969), Results of Probing Peak of Tension Tests Used in Other Crimes and Its Relation to the Suspected Conditions, Research Materials, No. 53, Polygraph Reports, National Research Institute of Police Science.

(10) Jaworski R. (2001), Application of Situational Sequencing Test in the Case of Police Officers Suspected of Murder and POT Tests as 'Knowledge of the Perpetrator Test', Journal of Forensic Identification, Vol. 51, No. 2.

(11) Jaworski R. (2003), The Significance of Situational Sequencing Tests in Establishing the Participation of Two Persons in a Murder Case and Hiding the Corpse, Journal of Forensic Identification, Vol. 53, No. 2.

(12) Jaworski R. (2006), Further Investigation Supports the Accuracy of Polygraph Examinations, Journal of Forensic Identification, Vol. 56, No. 5.

(13) Jaworski R. (2008), Multi-subject polygraph examination, Wydawnictwo Uniwersytetu Wrocławskiego [Wrocław University Press], Wrocław.

(14) Jaworski R. (2008), The validity of Polygraph Examination of an Innocent Person and a Perpetrator Administered Several Years after a Murder, European Polygraph, Vol. 1, No. 3 . 
(15) Jaworski R. (2011), Personalization and Calibration of the Control Question in the Control Question Test, Journal of Forensic Identification, Vol. 61, No. 5.

(16) Johnston A. (1958), The magic lie detector, Saturday Evening Post, April 1944; quoted from: Academy Lectures on Lie-Detection, Vol. 2, Springfield [about Leonard Keeler].

(17) Lykken D. (1981), A tremor in the blood, Perseus Books, New York.

(18) Matte J.A. (1996), Forensic Psychophysiology. Using the Polygraph. Scientific Truth Verification - Lie Detection. J.A.M. Publications, Williamsville, New York.

(19) Nakayama M. (2002), Practical Use of the Concealed Information Test for Criminal Investigation in Japan [in:] M. Kleiner (ed.), Handbook of Polygraph Testing, Academic Press, London.

(20) National Research Council (2003), The Polygraph and Lie Detection, Committee to Review the Scientific Evidence on the Polygraph. Division of Behavioral and Social Sciences and Education. Washington DC, The National Academies Press.

(21) Ohkawa H. (1963), Comparison of Physiological Response of 'Yes', 'No', and 'Mute' Conditions In Peak of Tension Test. Reports of the National Institute of Police Science, Japan, No. 1-4.

(22) Ohmishi K., Matsuno K., Arasuna M., Suzuki A. (1976), The objective Analysis of Physiological Indices in the Field Detection of Deception, Reports of the National Institute of Police Science, Vol. 29, No. 3.

(23) Reid J., Inbau F.E. (1977), Truth and Deception: The Polygraph ('Lie Detector') Technique, Baltimore, Williams and Wilkins.

(24) Saldziunas V., Kovalenko A. (2008), The Event Knowledge Test (EKT) in Polygraph Examination (in case murder), European Polygraph, Vol. 2, No. 2 (4).

(25) Saldziunas V., Kovalenko A. (2008), The Event Knowledge Test (EKT) In Polygraph Examination, European Polygraph, Vol. 2, No. 3-4 (5-6).

(26) Saldziunas V., Kovalenko A. (2011), A Little About Memory Traces, European Polygraph, Vol. 5, No. 1 (15).

(27) Saldziunas V., Kovalenko A., Knyazev V. (2012), Tests with Numbers, European Polygraph, Vol. 6, No. 1 (19).

(28) Widacki J. (1981), Wprowadzenie do problematyki badań poligraficznych, Warszawa.

(29) Wilkerson O.M. (1978), The Peak of Tension Tests Utilized in the Ashmore Kidnapping, Polygraph, Vol. 7, No. 1. 